\title{
Acute appendicitis within incisional hernia sac: a unique case report
}

\author{
Mohamed G. Issa
}

\begin{abstract}
Background: Incisional hernia appendicitis is a rare form in which the vermiform appendix is located within the hernial sac. It is seen in less than 1\% of inguinal hernia. Most often, the cases are misdiagnosed as incarcerated or strangulated hernia.

Case presentation: A 59-year-old female with history of hysterectomy 10 days ago for fibroid, came to the emergency department with diffuse abdominal pain and severe vomiting and absolute constipation for 3 days. Abdominal U/S was done and revealed inflamed fat within the hernia sac along with minimal collection. A defect was seen at the anterior abdominal wall measuring about $2.4 \mathrm{~cm}$ passing bowel loops and collection. CT scan with IV contrast revealed an inflamed appendix passing through the incisional hernia.

Conclusions: Appendicitis within a hernia sac is unusual with the incidence being $0.13 \%$ of all acute appendicitis. Acute hernia appendicitis is almost never been diagnosed prior to surgery. Most often, the diagnosis is incarcerated or strangulated hernia. The differential diagnosis should include hernia sac appendicitis for patients with signs of inflammatory process ongoing at the hernia sac.
\end{abstract}

Keywords: Incisional hernia, Appendicitis, Abdominal pain

\section{Background}

Appendicitis is a condition in which the appendix becomes inflamed, swollen, or infected. The annual incidence of appendicitis is 1 per 1000 person. Incisional hernia appendicitis is a rare form in which the vermiform appendix is located within the hernial sac. It is seen in less than $1 \%$ of inguinal hernia.

Acute appendicitis is a common surgical emergency. The presence of an inflamed appendix in an incisional hernia is rare. Incisional hernias complicate both open and laparoscopic surgery [1]. The overall incidence of appendicitis occurring within an inguinal, femoral, or incisional hernia estimated between $0.08-1 \%$ [2].

Presented is a case of appendicitis passing in through a Pfannenstiel incision. U/S and CT with IV contrast imaging have been done for the diagnosis.

Correspondence: Drmohammedgamal22@gmail.com

Radiology Department, Suez Canal University, 4.5 km, Ring Road, Ismailia 41522, Egypt
The appendix was seen inflamed being extended through a defect at the right side of the Pfannenstiel incision. Appendectomy and anterior abdominal repair were done. The main differential diagnosis for incisional hernia appendicitis is incarcerated or strangulated hernia. It should be in the differential diagnosis list for cases with lower abdominal pain and previous operation history.

\section{Case presentation}

A 59-year-old female with history of hysterectomy 10 days ago for fibroid, came to the emergency department with diffuse abdominal pain and severe vomiting and absolute constipation for 3 days. No evidence of genitourinary symptoms. A diagnosis of bowel loop obstruction was suspected. Pelvi-abdominal U/S was done and revealed inflamed fat within the hernia sac along with minimal collection and a localized pocket seen at right iliac fossa. A defect was seen at the anterior abdominal wall measuring about $2.4 \mathrm{~cm}$ passing

\section{Springer Open}

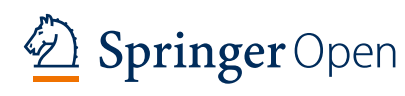

(c) The Author(s). 2020 Open Access This article is licensed under a Creative Commons Attribution 4.0 International License, which permits use, sharing, adaptation, distribution and reproduction in any medium or format, as long as you give appropriate credit to the original author(s) and the source, provide a link to the Creative Commons licence, and indicate if changes were made. The images or other third party material in this article are included in the article's Creative Commons licence, unless indicated otherwise in a credit line to the material. If material is not included in the article's Creative Commons licence and your intended use is not permitted by statutory regulation or exceeds the permitted use, you will need to obtain permission directly from the copyright holder. To view a copy of this licence, visit http://creativecommons.org/licenses/by/4.0/. 


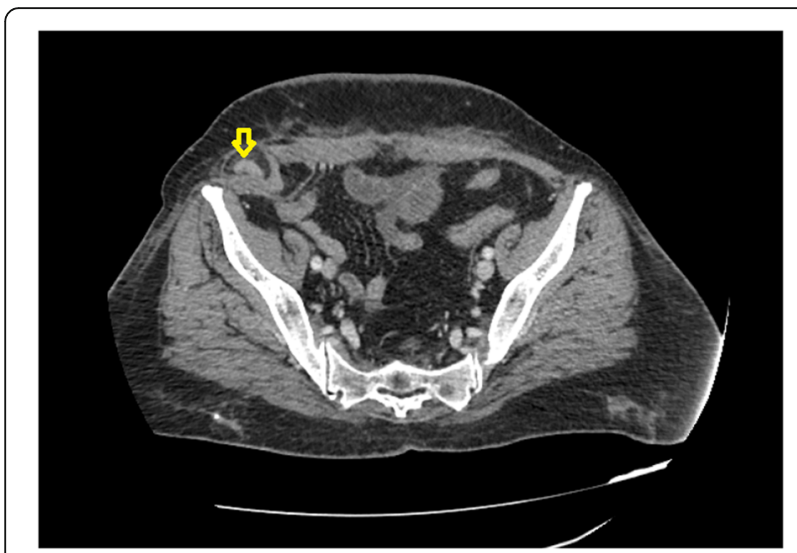

Fig. 1 Axial $C T$ with IV contrast showing the inflamed appendix (yellow arrow) passing through the hernia defect. Noted fat stranding and rim of fluid collection surrounding the appendix

bowel loops and collection. Visualized parts of bowel loops were not dilated. Caecum could not be assessed by U/S. The first differential diagnosis was incarcerated hernia. CT scan with IV contrast was done, and revealed that the appendix was passing through the incisional hernia along with bowel loops surrounded by fat stranding and signs of inflammatory process (Figs. 1 and 2). The bowel loops were not dilated. Surgical intervention was done and the appendix was seen inflamed and gangrenous mainly at its tip. It has been resected, and repair of the anterior abdominal wall was done.

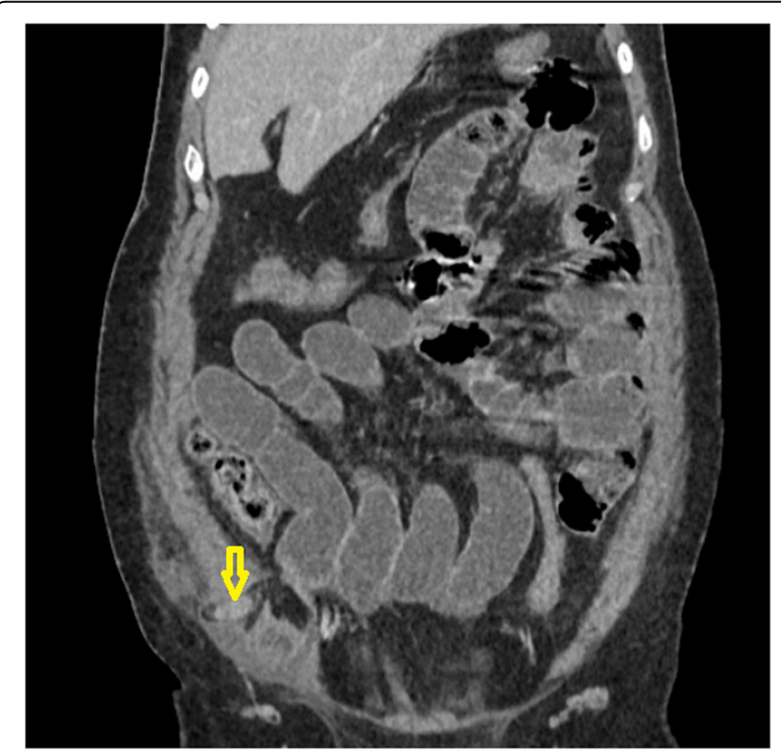

Fig. 2 Coronal CT with IV contrast the inflamed appendix (yellow arrow) passing through the hernia defect. Noted fat stranding and rim of fluid collection surrounding the appendix

\section{Conclusion}

It is estimated that 250,000 cases of acute appendicitis are diagnosed annually in the USA [3]. Appendicitis diagnosis depends on the clinical assessment as well as radiological imaging. The most common used criteria for appendicitis diagnosis is the Alvarado score. Presence of high score is a satisfactory aid in the early diagnosis of appendicitis in men and children; however, high false positive rates were seen in women [4].

Appendicitis within a hernia sac is unusual with the incidence being $0.13 \%$ of all acute appendicitis. Acute hernia appendicitis is almost never been diagnosed prior to surgery. Most often, the diagnosis is incarcerated or strangulated hernia [5].

Grey scale ultrasound has great aid in the diagnosis of acute appendicitis with sensitivity of $87 \%$, specificity of $92 \%$, and accuracy of $93 \%$ [6]. As appendicitis may present within hernias, there should be a low threshold for computed tomography assessment of hernias when there is clinical doubt about the symptoms associated with the hernia [7].

\section{Abbreviations}

CT: Computed tomography; U/S: Ultrasound; IV: Intravenous

\section{Acknowledgements}

Not applicable.

\section{Author's contributions}

Mohamed Issa is the main author who gathered the data, wrote the manuscript, and submitted it to the journal. The authors read and approved the final manuscript.

\section{Funding}

Not applicable.

\section{Availability of data and materials}

(1) DOI: $10.6084 / \mathrm{m} 9$.figshare. 8224280

(2) https://figshare.com/s/135c03df584daaf92f10

The data used and/or analyzed during the current study are available from the corresponding author on reasonable request.

\section{Ethics approval and consent to participate}

This case report was approved by the Research Ethics Committee of the Faculty of Medicine at Suez Canal University in Egypt on Jan./11/2020; reference number of approval: PA-10-2020. The patient included in this study gave written informed consent to participate in this research.

\section{Consent for publication}

Written informed consent was obtained from the patient for publication of this case report and accompanying images.

\section{Competing interests}

The author declares that he has no competing interests.

\section{Received: 20 December 2019 Accepted: 17 March 2020}

\section{(1)}

\section{References}

1. Sugrue C, Hogan A, Robertson I, Mahmood A, Khan WH, Barry K (2013) Incisional hernia appendicitis: a report of two unique cases and literature review. Int J Surg Case Rep. 4(3):256-258

2. Galiñanes EL, Ramaswamy A (2012) Appendicitis found in an incisional hernia. J Surg Case Rep 2012(8):3 
3. Addiss DG, Shaffer N, Fowler BS, Tauxe RV (1990) The epidemiology of appendicitis and appendectomy in the United States. Am J Epidemiol. 132(5):910-925

4. Kalan M, Talbot D, Cunliffe WJ, Rich AJ (1994) Evaluation of the modified Alvarado score in the diagnosis of acute appendicitis: a prospective study. Ann R Coll Surg Engl 76(6):418

5. Carey LC (1967) Acute appendicitis occurring in hernias: a report of 10 cases. Surgery 61(2):236-238

6. Quillin SP, Siegel MJ (1994) Appendicitis: efficacy of color Doppler sonography. Radiology 191(2):557-560

7. Al-Hadithy N, Erotocritou P, Portou MJ, Hamilton H (2010) Appendicitis in an incisional hernia after radical nephrectomy: a case report. Ann R Coll Surg Engl. 92(6):e23-e24

\section{Publisher's Note}

Springer Nature remains neutral with regard to jurisdictional claims in published maps and institutional affiliations.

\section{Submit your manuscript to a SpringerOpen ${ }^{\circ}$ journal and benefit from:}

- Convenient online submission

- Rigorous peer review

- Open access: articles freely available online

High visibility within the field

- Retaining the copyright to your article

Submit your next manuscript at $\boldsymbol{\nabla}$ springeropen.com 